\title{
Histone acetylation is recruited in consolidation as a molecular feature of stronger memories
}

\author{
Noel Federman, Maria Sol Fustiñana, and Arturo Romano ${ }^{1}$ \\ Laboratorio de Neurobiología de la Memoria, Departamento de Fisiología, Biología Molecular y Celular, Facultad de Ciencias \\ Exactas y Naturales, Universidad de Buenos Aires, IFIByNE (UBA CONICET), Ciudad Universitaria, 1428EHA Buenos Aires, Argentina
}

\begin{abstract}
Gene expression is a key process for memory consolidation. Recently, the participation of epigenetic mechanisms like histone acetylation was evidenced in long-term memories. However, until now the training strength required and the persistence of the chromatin acetylation recruited are not well characterized. Here we studied whether histone acetylation is involved in consolidation in invertebrates, whether it depends on the training strength, and whether it is a permanent or transient mechanism. We used a well-characterized memory model in invertebrates, the context-signal memory in crabs. Our results show no changes in histone $3(\mathrm{H} 3)$ acetylation during consolidation of a standard training protocol. However, strong training induced a significant increase in $\mathrm{H3}$ acetylation 1-h post-training, returning to basal levels afterward. Accordingly, the administration of histone deacetylase inhibitors sodium butyrate $(\mathrm{NaB})$ and trichostatin A allowed a weak training to induce long-term memory. NaB enhanced memory in two phases during consolidation. These findings support that $\mathrm{H3}$ acetylation (1) is involved in consolidation, (2) occurs only after strong training, (3) is a transient process, and (4) memory is enhanced in two phases. The coincidence of these phases with other mechanisms of gene expression is discussed.
\end{abstract}

Regulation of gene expression is postulated as a critical process for long-lasting storage of memories (Agranoff et al. 1967; Goelet et al. 1986). In order to persist, memory storage involves changes in the gene expression pattern. Involvement of epigenetic mechanisms was postulated to provide potentially stable marks in the genome for continuous regulation of specific gene expression (Tsankova et al. 2004; Kumar et al. 2005) (for review, see Colvis et al. 2005; Hsieh and Gage 2005; Levenson and Sweatt 2006; Barret and Wood 2008). Chromatin structure and function can be affected by various post-translational modifications of the amino-terminal tails of nucleosomal histones (Strahl and Allis 2000; Kouzarides 2007). Lysine acetylation is one of the best-characterized histone modifications. Chromatin modifying enzymes, which carry out protein acetylation and deacetylation, have already been described (Sterner and Berger 2000): histone acetyl transferases (HATs), such as CREB-binding protein (CBP/p300) and histone deacetylases (HDACs), respectively. Histone acetylation induces transcription activation by increasing DNA accessibility to the transcription machinery (Norton et al. 1989; Vettese-Dadey et al. 1996). Recruitment of epigenetic mechanisms, such as histone acetylation, methylation, and phosphorylation, has already been described for long-term plasticity and for vertebrate memory consolidation (Guan et al. 2002; Alarcon et al. 2004; Korzus et al. 2004; Wood et al. 2005, 2006a). In agreement with such findings, HDAC inhibitors' administration improved long-term memory in rats and mice (Levenson et al. 2004; Yeh et al. 2004; Fischer et al. 2007; Vecsey et al. 2007) and reverted memory deficits induced by genetic manipulation of the CBP gene (Alarcon et al. 2004; Korzus et al. 2004).

The interaction between transcription factors and chromatin is regulated by means of histone acetylation-deacetylation. In such a way, stable changes in gene expression are achieved by this regulation, which could be an important mechanism in the

\footnotetext{
'Corresponding author.
}

E-mail aromano@fbmc.fcen.uba.ar; fax 54-11-45763447.

Article is online at http://www.learnmem.org/cgi/doi/10.1101//m.1537009. consolidation process for the stability of long-term memory. However, to our knowledge, the steady state of the chromatin has not been evaluated, either during or after memory consolidation. In addition, although the first evidence of histone acetylation in neural plasticity was obtained in the mollusk Aplysia's long-term facilitation of the sensory-motor neurons synapses (Guan et al. 2002), until now no direct evidence has been reported for chromatin modifications in long-term memory in invertebrates. Here we evaluate whether acetylation of histones is involved in memory consolidation and whether memory can be improved by HDAC inhibition in an invertebrate model. For such purposes, we made use of a well-characterized memory model, the context-signal memory (CSM), in the crab Chasmagnathus. In CSM, repeated presentation of a visual danger stimulus (an opaque screen that moves above the animal) provokes the fading of the initial escape response, which is actively replaced by a freezing response (Lozada et al. 1990). Fifteen or more spaced danger stimulus presentations induce an association between the iterated stimulus and contextual features. A long-term memory is formed, which lasts at least for a week and entails de novo protein synthesis and mRNA synthesis (Pedreira et al. 1996), activation of camp-dependent protein kinase (PKA) (Locatelli et al. 2000, 2002), activation of extracellular-signal-regulated kinase (ERK) (Feld et al. 2005), and activation of the NF- $\mathrm{B}$ transcription factor (Freudenthal and Romano 2000; Merlo et al. 2002).

The aim of the present work is to define the necessary training parameters to induce histone acetylation and to describe the time course of this process during memory formation. Using the crab memory paradigm we found that histone $3(\mathrm{H} 3)$ is acetylated $1 \mathrm{~h}$ after training in the central brain during CSM consolidation. This change was induced only after strong training. In agreement with these findings, administration of the HDAC inhibitor sodium butyrate $(\mathrm{NaB})$ produced memory enhancement, allowing a weak training protocol of five trials to induce long-term memory. Our results suggest that histone acetylation is recruited in consolidation as one of the molecular features of stronger memories. 


\section{Results}

\section{Effect of the HDAC inhibitor sodium butyrate $(\mathrm{NaB})$ on long-term memory}

Sodium butyrate $(\mathrm{NaB})$ is a widely used HDAC inhibitor. Previous reports indicated that inhibition of HDACs induces memory facilitation in mammalian memory models (Levenson et al. 2004; Yeh et al. 2004; Fischer et al. 2007; Vecsey et al. 2007). In order to evaluate whether the inhibition of HDACs induces memory enhancement in the crab CSM, we administered $\mathrm{NaB}$ at different time points pre- and post-training.

In the first experiment, a group of crabs was injected with $\mathrm{NaB}$, while another group was injected with saline solution (SS). Immediately after the injection, all were placed in the actometers. Half of the animals of each group were trained (TR) 10 min later and the other half remained untrained as controls (CT), producing four groups, CT-SS, TR-SS, CT-NaB, and TR-NaB, of 40 crabs each. Figure $1 \mathrm{~A}$ shows the results of the training session, indicating that drugs injected before training did not affect the acquisition phase (repeated-measures ANOVA, nonsignificant). Twenty-four hours later, all groups were tested. As shown in Figure 1B, nonsignificant differences were found between CT-SS and TR-SS, as expected for a weak training. On the contrary, comparison of CT-NaB and TR$\mathrm{NaB}$ disclosed significant differences $\left(F_{(1,140)}=4.2 ; P<0.05\right)$. These last statistical differences suggest that HDAC inhibitor caused memory enhancement by allowing a weak training to induce long-term retention. However, the comparison between TR-SS and TR-NaB showed no significant differences, suggesting that the memory facilitatory effect of $\mathrm{NaB}$ would be partial at this time point.

In the following experiment with the same groups' design, crabs were injected with $\mathrm{NaB}$ or SS immediately after training. As shown in Figure 2A there are no differences between CT-SS and TRSS, but significant differences between CT-NaB vs. TR-NaB were found $\left(F_{(1,108)}=4.0 ; P<0.05\right)$, indicating a memory enhancement effect of the drug. Unlike the previous experiment, there were also significant differences between TR-SS and TR-NaB $\left(F_{(1,108)}=3.8\right.$; $P<0.05)$, supporting a strong memory-enhancement effect of the HDAC inhibitor injection at this time point.

In the third experiment, animals were injected $3 \mathrm{~h}$ after training and, in this case, no significant differences were found for any pair of CT-TR group comparisons (Fig. 2B). The result of this experiment suggests that the time window for $\mathrm{NaB}$ facilitation effect in consolidation is shorter than $3 \mathrm{~h}$. However, in previous studies in the crab CSM, a second phase of PKA and NF-kB activity in consolidation was found (Freudenthal and Romano 2000; Locatelli and Romano 2005), and experiments with drugs that inhibit PKA and NF-kB activity showed a second phase of drug action during consolidation, around $6 \mathrm{~h}$ after training. Thus, we evaluated a possible second phase of memory facilitation by $\mathrm{NaB}$ in a fourth experiment in which the animals were injected $6 \mathrm{~h}$ after training. In agreement with previous findings, we found no differences between CT-SS and TR-SS, but significant differences between CT-NaB vs. TR-NaB $\left(F_{(1,106)}=9.3 ; P<0.01\right)$, and between TR-SS and TR-NaB $\left(F_{(1,106)}=4.8 ; P<0.05 ;\right.$ Fig. 2 C) supporting, once again, a strong memory enhancement effect of the HDAC inhibitor injection.

Finally, we performed an experiment with the same groups' design, but injecting animals at $12 \mathrm{~h}$ after training. In this experiment no significant differences were found in any group comparisons (Fig. 2D), suggesting that at $12 \mathrm{~h}$ the time window of HDAC inhibitor effect is closed, and thus it is not possible to induce a memory enhancement by injecting $\mathrm{NaB}$.

In the five experiments presented in this first section, no differences were found in the CT-Sal vs. CT-NaB comparisons, indicating that the drug did not alter normal levels of response of untrained animals, demonstrating nonspecific effects.

\section{Effect of trichostatin A on long-term memory}

While $\mathrm{NaB}$ inhibits HDACs, it is also a putative inhibitor of chloride channels and phosphodiesterases (Resta-Lenert et al. 2001). Therefore, we evaluated the effect of an HDAC inhibitor structurally unrelated with $\mathrm{NaB}$, Trichostatin A. We made the experiment with the same groups' design as in the case of $\mathrm{NaB}$ injections, but the crabs were injected with doses of TSA or DMSO as vehicle immediately after training. In agreement with the findings in the experiments with $\mathrm{NaB}$ injection immediately post-training (Fig. 2A), we found no differences between CTDMSO and TR-DMSO groups, but significant differences between CT-TSA vs. TR-TSA $\left(F_{(1,122)}=7.12 ; P<0.01 ;\right.$ Fig. 3$)$. Similar to the pretraining injection of $\mathrm{NaB}$ (Fig. 1), the comparison between TRDMSO and TR-TSA shows no significant differences, suggesting that at this time point the facilitatory effect is partial. Nevertheless, this result supports that the memory-enhancement effect of $\mathrm{NaB}$ is due to inhibition of HDACs.

\section{Effect of $\mathrm{NaB}$ injection on the level of histone acetylation in the crab's central brain}

Previous experiments suggest that HDAC inhibition by $\mathrm{NaB}$ administration induced an increment in chromatin acetylation. As a consequence of the increased level of histone acetylation, long-term memory is improved, probably due to an enhancement of gene expression. In order to obtain evidence that histone acetylation is increased in the crab brain after $\mathrm{NaB}$ injection, we performed the following experiment: Three groups of 20 animals were injected with $\mathrm{NaB}$ at the same dose used in all of the experiments of the first two sections. At 15,30 , or 60 min after injection, animals were sacrificed and the central brain was dissected. A noninjected naïve group (NV) and a SS-injected group sacrificed at 15 min were included as controls. Histone-enriched protein extracts were obtained from a pool of 20 central brains for each group and Western blots were performed using acetylspecific H3 antibody. The intensity of the specific band obtained with this antibody was estimated by densitometry, relative to the densitometric values obtained with an $\mathrm{H} 3$ total antibody. Figure $4 \mathrm{~A}$ shows mean \pm SE of the relative optic density (ROD) values with respect to
Figure 1. Effect of pretraining injection of the HDAC inhibitor sodium butyrate $(\mathrm{NaB})$ during memory consolidation. (A) Training session after pretraining drug injection. (B) Escape response at testing session with pretraining injection. Mean response level \pm SEM. $\left(^{*}\right) P<0.05$. 


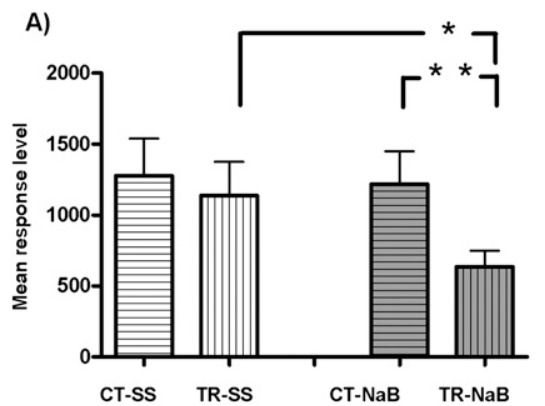

C)

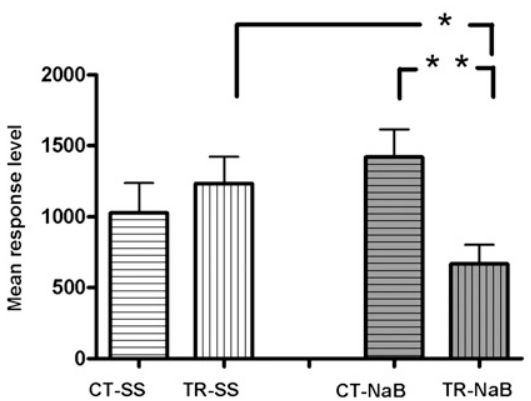

B)

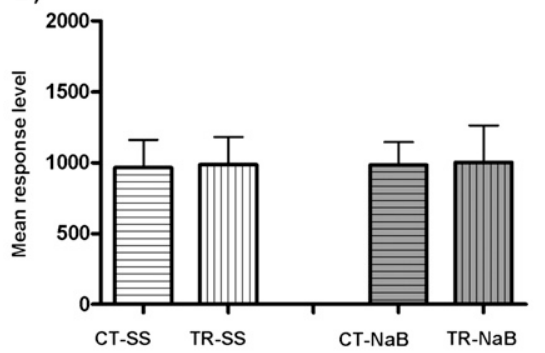

D)

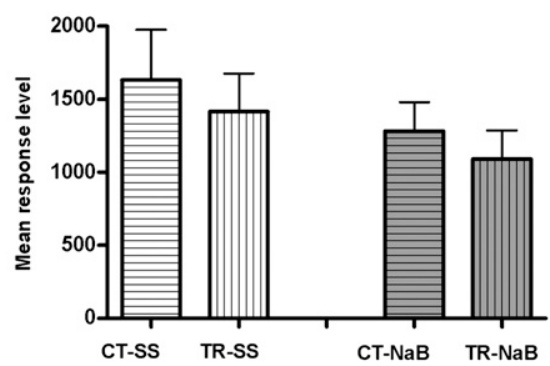

Figure 2. Effect of immediate, 3-, 6-, and 12-h post-training injections of sodium butyrate ( $\mathrm{NaB})$ during memory consolidation. (A) Escape response at testing session with immediate post-training injection. (B) Escape response at testing session of the 3-h post-training injection experiment. (C) Escape response at testing session of the 6-h post-training injection experiment. (D) Escape response at testing session of the 12 -h post-training injection experiment. Mean response level \pm SEM at testing. $\left(^{*}\right) P<$ $0.05 ;(* *) P<0.01$.

training, and this increment was transient, returning to basal levels $6 \mathrm{~h}$ after training.

\section{Levels of histone acetylation during memory facilitation by HDAC inhibition}

In order to gain insight into the modulation of memory formation by HDAC inhibition, we studied whether a weak training protocol plus a HDAC inhibitor injection creates an increase of histone $\mathrm{H} 3$ acetylation as strong training does. A noninjected naïve group (NV) and a weak training protocol plus a SS injection (weakTR+SS) group were used as controls. Since we have seen significant differences during the consolidation of strong memory at 1 -h post-injection (Fig. 5), we measured histone $\mathrm{H} 3$ acetylation at this time point after weak training. Four independent experiment repetitions were carried out. Figure 6 shows the results in which a significant increment of $\mathrm{H} 3$ acetylation level was found $1 \mathrm{~h}$ after weak training in the $\mathrm{NaB}$ (weakTR+NaB) group compared with both control groups (Student's $t$-test, $P<0.05)$. Thus, HDAC inhibition facilitates memory by means of increasing the histone $\mathrm{H} 3$ acetylation level $1 \mathrm{~h}$ after a weak training protocol. the NV group from five independent experiments. A significant increase of $\mathrm{H} 3$ acetylation was found $15 \mathrm{~min}$ (general ANOVA $F_{(3,14)}=4.9, P<0.01$; Duncan test, $\left.P<0.01\right)$ and 30 min after NaB injection (Duncan test, $P<0.05$ ) in comparison with SS-15 min, decreasing at $60 \mathrm{~min}$ after injection (Duncan test, NS).

\section{Time course of histone acetylation during memory consolidation}

The following experiments were aimed at evaluating the level of H3 acetylation during memory consolidation. In the first series of experiments, crabs were trained (TR group) with the standard 15 trials of training protocol that induces long-term memory (Pedreira et al. 1998) or remained in the actometers without stimulation (CT group). A naïve (NV) group was added, as described in the Materials and Methods section. Twenty crabs per group were used. These three groups were repeated for each time point after training: $0,1,6$, and $24 \mathrm{~h}$. Four independent experiment repetitions were carried out for each time point. As showed in Figure $4 \mathrm{~B}$, no changes were found in the mean level of $\mathrm{H} 3$ acetylation with respect to the mean basal level of $\mathrm{NV}$ at any time after standard training.

In the second series of experiments 30 trials of strong training protocol were used. In these experiments the procedure used was the same as in the first series. Figure 5 shows the results in which a significant increase in $\mathrm{H} 3$ acetylation level was only found $1 \mathrm{~h}$ after training in the TR group compared with the NV and CT groups (general ANOVA, $F_{(2,6)}=7.7, P<0.05$; Duncan test, $P<0.01$ and $P<0.05$, respectively). Comparison between $\mathrm{NV}$ and CT showed no significant differences.

Thus, the level of $\mathrm{H} 3$ acetylation was increased in the crab brain $1 \mathrm{~h}$ after a strong training protocol, but not after a standard

\section{Discussion}

In the present work two independent lines of evidence support that histone acetylation is required in consolidation for stronger memories. The first line of evidence demonstrates that the HDAC inhibitor $\mathrm{NaB}$, which increases histone acetylation (Fig. 4A), enhanced long-term memory during the consolidation phase. Systemic delivery of $\mathrm{NaB}$ prior to or after a weak training allowed for retention $72 \mathrm{~h}$ later (Figs. 1, 2A). On the contrary, animals administered saline solution showed no retention, as expected for the weak training used. Furthermore, we found that a weak training did not, in fact, induce histone $\mathrm{H} 3$ acetylation in the saline-injected group, but the injection of $\mathrm{NaB}$ increased $\mathrm{H} 3$ acetylation $1 \mathrm{~h}$ after weak training (Fig. 6), similar to the increment found after strong training without injection (Fig. 5).

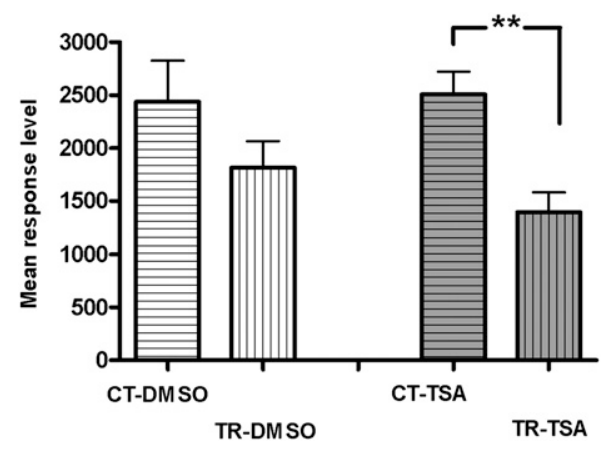

Figure 3. Effect of immediate post-training injection of the HDAC inhibitor TSA during memory consolidation. Escape response at testing session with immediate post-training injection. Mean response level \pm SEM at testing. $\left.{ }^{* *}\right) P<0.01$. 
A)

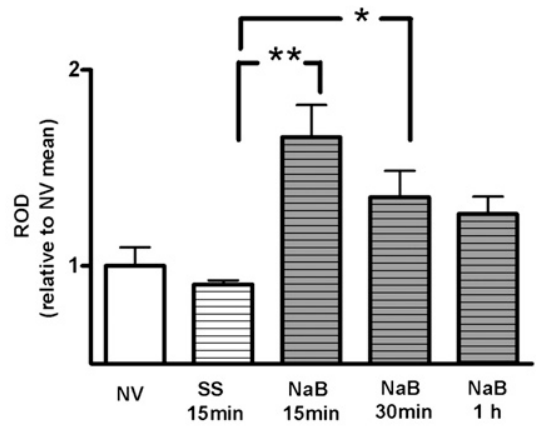

B)

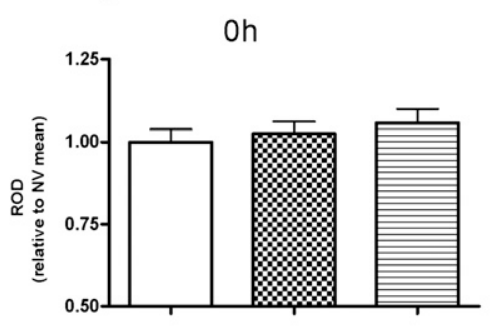

$6 \mathrm{~h}$

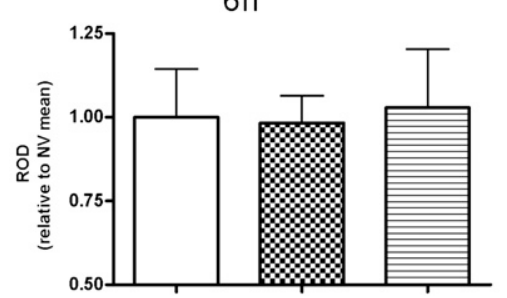

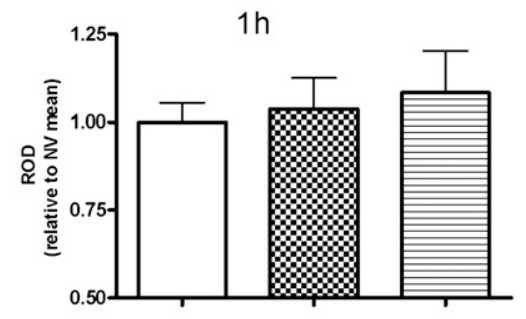

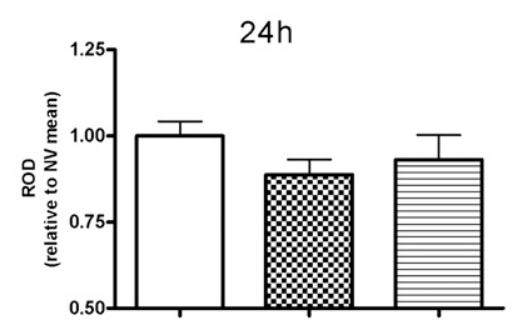

Figure 4. Levels of histone $\mathrm{H} 3$ acetylation in the crab brain. $(A)$ Effect of sodium butyrate $(\mathrm{NaB})$ injection on the level of histone acetylation. Mean \pm SEM of ROD values of the specific acetyl histone $\mathrm{H} 3$ band normalized to NV group mean value. Results obtained from five independent experiments. Duncan test, $\left({ }^{*}\right) P<0.05,\left(^{* *}\right) P<0.01$. (B) Time course of histone acetylation during memory consolidation after standard training. Mean \pm SEM of ROD values of the specific acetyl histone $\mathrm{H} 3$ band normalized to NV group mean value. Results obtained from four independent experiments; Duncan test.

It is known that $\mathrm{NaB}$ inhibits Class I (nuclear localization) and Class II (shuttle between nucleus and cytoplasm) HDACs, resulting in increased histone acetylation and, therefore, facilitating gene transcription (Marks et al. 2004; Dokmanovic and Marks 2005). Gene expression is a critical requirement for the conversion of a labile short-term memory into a consolidated long-term memory. In a previous work, we found that a weak training protocol of five trials is unable to recruit sufficient activation of a transcription factor, NF-кB (Freudenthal and Romano 2000), in order to induce long-term memory. Our present results suggest that gene-transcription facilitation induced by the HDAC inhibitor may enable the amount of mRNA synthesis required to transform a weak memory trace in a stronger long-term memory. Furthermore, NaB showed two phases of facilitation after training, the first one when administered immediately after training and the other $6 \mathrm{~h}$ after training. This effect was not found at 3 or $12 \mathrm{~h}$ after training. These two time windows for drug effect fit well with two phases of PKA activity after training and two time windows for PKA inhibitor effect found in this memory model (Locatelli et al. 2002; Locatelli and Romano 2005), suggesting that camp-dependent gene expression is involved in these two phases. Similarly, two phases of NF-кB activation after training (Freudenthal and Romano 2000) and two time windows of NF-кB inhibitor effect (Merlo et al. 2002) were found within the same time periods. Our results suggest that an increased $\mathrm{H} 3$ histone acetylation level by $\mathrm{NaB}$ injection during these two phases could compensate the lack of

NF-кB-dependent transcriptional induction after a weak training (Freudenthal and Romano 2000). This increment allows for the basal transcriptional activity of this transcription factor, as well as others, to induce long-term memory formation.

In the second line of evidence, we found increased levels of H3 acetylation during CSM consolidation only after the strong training protocol. The antibody used for acetylated $\mathrm{H} 3$ detection was built to recognize acetylated lysines 9 and 14, both modifications previously associated with transcription activation in different taxa. There are two remarkable characteristics of this acetylation increment in consolidation: (1) Such an increment occurs only after 30 trials of strong training, indicating that not all long-term memory processes recruit this epigenetic mechanism, but only those that could induce a more persistent memory. This finding has an important interpretative consequence because all long-term memory is considered to require gene expression, and chromatin acetylation is indeed involved in transcription. Why then should there be differences between memory mechanisms induced by standard and strong training? We consider that there are genes normally accessible for the transcriptional machinery, while others require chromatin modifications to make them accessible to transcriptional functions (Saccani et al. 2001). Additionally, it has recently been shown that some genes, such as neural cell adhesion molecules (NCAM), are basally accessible in regulatory regions but undergo intragenic region histone modifications in order to change their transcription and splicing (Schor et al. 2009). Therefore, our findings support the idea that some genes or genic regions are made accessible only after a great induction, and this change of expression of such genes contributes to a more persistent memory formation. Due to the fact that we performed a bulk analysis, we could not determine whether there is any change in the level of histone acetylation in specific promoters after the standard protocol of training. Further experiments using the examination of the acetylation process in particular promoters will be necessary to fully understand this chromatin modification mechanism during memory formation and to evaluate the differences obtained between standard and strong protocols used; (2) the H3 acetylation increment is transient, decreasing to basal levels $6 \mathrm{~h}$ after training. This is the first study of a time course for histone acetylation in memory consolidation, showing the temporary nature of the regulation of this molecular process during memory formation. Memory strength is associated with different gene-expression patterns under the influence of modifications in the chromatin structure of those genes. Our results do not rule out that a mechanism of acetylation of other residues in H3 histone or of other nucleosomal histones can account for the transcription during consolidation of weaker memories, as was the case in 15 trials of training. There is evidence that suggests the existence of an epigenetic code that regulates specific geneexpression profiles for different memory formation processes (Wood et al. 2006b). 
A)

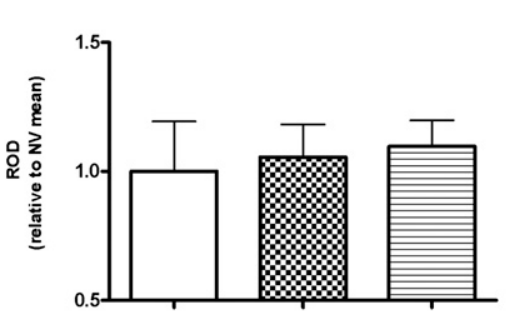

$6 \mathrm{~h}$

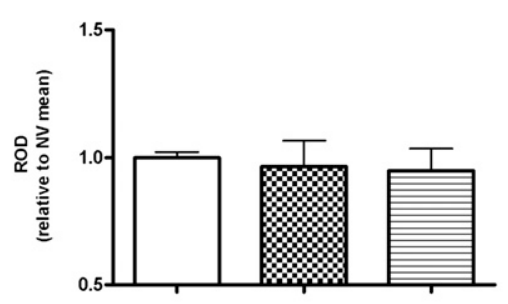

B)

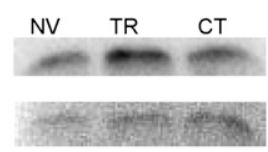

$1 \mathrm{~h}$

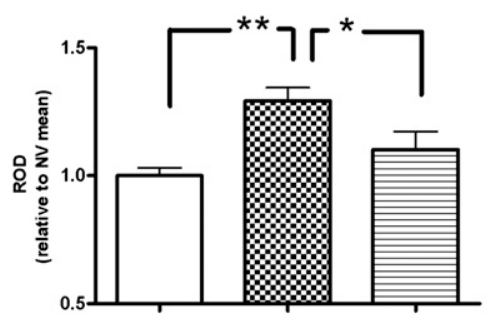

$24 \mathrm{~h}$

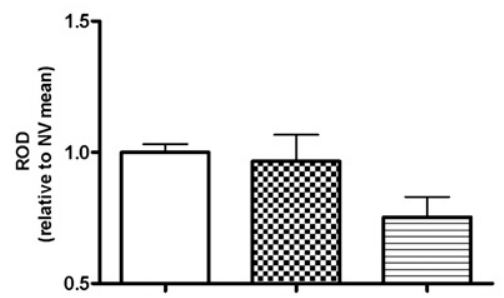

Acetyl histone $\mathrm{H3}$

Total histone $\mathrm{H}_{3}$

Figure 5. Time course of histone acetylation during memory consolidation after strong training. $(A)$ Mean \pm SEM of ROD values of the specific acetyl histone $\mathrm{H} 3$ band normalized to total $\mathrm{H} 3$ antibody ROD values and to NV group mean value. Results obtained from four independent experiments. Duncan test, $\left.\left(^{*}\right) P<0.05,{ }^{(*}\right) P<0.01$. (B) Representative Western blot of protein extracts from 1-h post-training animals performed with acetyl-specific $\mathrm{H} 3$ (top) and total $\mathrm{H} 3$ (bottom) antibodies.

Although $\mathrm{NaB}$ is a widely used drug to study the effect of HDAC inhibition on memory, it has been found in other effects not related to histone acetylation (Resta-Lenert et al. 2001). The fact that TSA injection also induced memory enhancement (Fig. 3) supports the action that $\mathrm{NaB}$ on memory is due to HDAC inhibition. Moreover, here we found increasing $\mathrm{H} 3$ acetylation at $1 \mathrm{~h}$ after weak training in the group injected with $\mathrm{NaB}$ (Fig. 6) in marked correlation with the increment induced by strong training (Fig. 5). These results suggest that the facilitatory effect of the drug is explained, at least in part, by increasing chromatin acetylation. Nevertheless, it is predictable that the increased acetylation induced by HDACs inhibition of other nuclear proteins different from histones could contribute to the memory facilitation effect observed. Although we did not explore this in the present study, we propose that the transcription factor NF-кB, a putative substrate of this enzyme (Sterner and Berger 2000; Yeh et al. 2004), could be another transcriptional regulation point that explains part of the effect that was found.

Our finding of an enhancing effect of HDAC inhibitors is consistent with previous results obtained in rodent memory models (Levenson et al. 2004; Yeh et al. 2004; Fischer et al. 2007; Vecsey et al. 2007). The results presented here and previous evidence in synaptic plasticity models in invertebrates, together with the previous evidence in vertebrates, support that histone acetylation is an evolutionarily conserved mechanism for gene expression regulation in consolidation of long-lasting memories.

\section{Materials and Methods}

\section{Animals}

Adult male Chasmagnathus granulatus intertidal crabs, $2.6-2.9 \mathrm{~cm}$ across the carapace, weighing $17 \pm 0.2 \mathrm{~g}(n=60)$, were collected

from water $<1-\mathrm{m}$ deep in the estuarine coasts of San Clemente del Tuyú, Argentina, and transported to the laboratory, where they were lodged in plastic tanks $(30 \times 45 \times 20 \mathrm{~cm})$ filled to 0.5 -cm depth with diluted $(12 \%$, pH 7.4-7.6) marine water (prepared from Cristalsea Marinemix salts), to a density of 20 crabs per tank. The holding room was maintained on a $12 \mathrm{~h}$ light-dark cycle (light on 07:00-19:00 h). The temperature of both holding and experimental rooms was maintained within a range of from $22^{\circ} \mathrm{C}$ to $24^{\circ} \mathrm{C}$. Experiments were carried out between the third and the tenth day after the animal's arrival. Each crab was used in only one experiment. Experiments were carried out in accordance with the local regulations for the care and use of laboratory animals. All efforts were made to minimize animal suffering and to reduce the number of animals used.

\section{Training-testing apparatus}

The experimental unit is described in detail elsewhere (Romano et al. 1990). Briefly, it consists of a bowl-shaped plastic container in which the crab is lodged and an opaque rectangular screen that moves horizontally above the animal. Screen displacements evoke the crab's running response, and, as a consequence, container vibrations that induce electrical signals through four piezoelectric transducers attached to the external surface of the container. Signals recorded during a trial were translated into numerical units ranging from 0 to 8000 . The experimental room had 40 units, separated from each other by partitions. A computer was used to program trial sequences, trial duration, and intertrial intervals, as well as to monitor experimental events.

A)

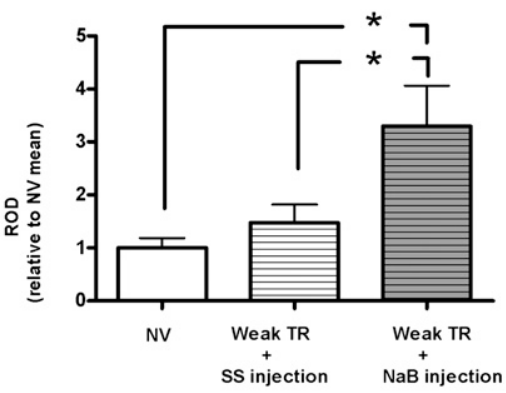

B)

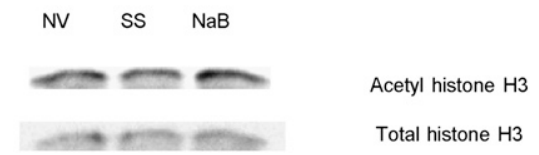

Figure 6. Levels of histone acetylation during memory facilitation by HDAC inhibitor injection. $(A)$ Mean \pm SEM of ROD values of the specific acetyl histone $\mathrm{H} 3$ band normalized to total $\mathrm{H} 3$ antibody ROD values and to NV group mean value. Results obtained from four independent experiments. Duncan test, $\left(^{*}\right) P<0.05$. (B) Representative Western blots performed with acetyl-specific $\mathrm{H} 3$ (top) and total $\mathrm{H} 3$ (bottom) antibodies. 


\section{Drugs and injection procedure}

Fresh sodium butyrate $(\mathrm{NaB})$ (Sigma) was dissolved in crustacean saline solution (SS) (Hoeger and Florey 1989). Fifty microliters of vehicle or $15 \mathrm{mM}$ of drug solution $(83 \mu \mathrm{g}$ per crab, $4.8 \mu \mathrm{g} / \mathrm{g})$ were given through the right side of the dorsal cephalothoracic-abdominal membrane by means of a syringe fitted with a sleeve to control depth of penetration to $4 \mathrm{~mm}$, thus ensuring that the injected solution was released roughly at the center of the pericardial sac. The total volume of hemolymph was estimated at $5 \mathrm{~mL}(30 \%$ of the body weight) (Gleeson and Zubkoff 1977) resulting in an approximate 100 -fold dilution of the drug in hemolymph. Trichostatin A (TSA) (Sigma) was dissolved in dimethylsulfoxide (DMSO). Ten microliters of vehicle or $6 \mu \mathrm{g} / \mu \mathrm{L}$ of drug solution $(60 \mu \mathrm{g}$ per crab, $3.5 \mu \mathrm{g} / \mathrm{g}$ ) were given.

\section{Procedure in memory evaluation experiments}

Each experiment lasted about $4 \mathrm{~d}$ and included two phases: training session (day 1) and testing session (day 4). Crabs were individually housed during the intersession interval in plastic containers, covered to a depth of $0.5 \mathrm{~cm}$ with marine water, and kept inside dimly lit drawers. In order to evaluate a potential enhancing effect of the drug on memory we used a weak training protocol that does not induce long-term memory. The training session consisted of five trials with an intertrial interval (ITI) of $171 \mathrm{sec}$. Each trial lasted 9 sec and consisted of two cycles of presentation of the screen over the actometer. Each cycle lasted $2.5 \mathrm{sec}$, with $2 \mathrm{sec}$ of interval between cycles. The crab's activity was recorded during the entire trial time. The testing session consisted of one trial. Both the training and testing sessions were preceded by $10 \mathrm{~min}$ of adaptation in the apparatus. The unit used during the training session is referred to as the training context. In all experiments, one group was trained (TR group), while the other was located in the device but remained untrained (control group, CT group). Each experiment consisted of a pair from the CT-TR group injected with the vehicle (SS pair or DMSO pair) and another pair injected with the drug (NaB pair or TSA pair), $n=30-40$ for each group.

\section{Data analysis in drug effect evaluation}

Retention of learning acquired during training was considered when a statistically lower level of response in the testing session was found for the TR group relative to the CT group injected with the same solution (drug or vehicle). This criterion came from previous experiments performed in our laboratory in which a significant difference ( $t$-test, $\alpha=0.05$ ) between trained (TR) and untrained groups (CT) was invariably disclosed at testing session $24 \mathrm{~h}$ or more, after 15 or more trial training protocols (ITI $=171 \mathrm{sec}$ ). Such significant differences were also found when crabs were injected with vehicle at various pre- and post-training intervals. Accordingly, predictions were for a significant difference between CT and TR groups in the testing session. Therefore, throughout this study results of the behavioral study were analyzed with a priori-planned comparisons using a weighted-means ANOVA with $\alpha$ (per comparison error rate) $=0.05$, according to the standard method (Howell 1987). The lack of difference between CT and TR groups is thus assumed as no memory retention. A comparison between CT groups injected with drug or vehicle was necessary in order to determine incidental drug effects affecting response levels at testing in a way not related to the training experience. In general, the statistical analysis of testing data included a set of three a priori-planned comparisons, namely, CT-Vehicle vs. TR-Vehicle, CT-Drug vs. TRDrug, and TR-Vehicle vs. TR-Drug, using a weighted-means ANOVA with $\alpha$ (per comparison error rate) $<0.05$ (Howell 1987). In the first comparison, no difference between the CT-Vehicle vs. TR-Vehicle groups was expected due to the use of a weak training protocol in the last group. On the contrary, if the drug enhanced memory, differences in the comparisons between CT-Drug and TR-Drug groups and between TR-Vehicle vs. TR-Drug groups were expected.

\section{Training procedure in acetyl-H3 evaluation} from brain histone-enriched extracts

Crabs were trained either using the standard training protocol of 15 trials (45-min duration) or the strong training protocol of 30 trials (90-min duration), both of which induce long-term memory, but the change in behavior is more pronounced at testing using the strong protocol (Freudenthal et al. 1998; Pedreira et al. 1998). In the consolidation-phase experiments, crabs were sacrificed at different time points after training $(0,1,6$, and $24 \mathrm{~h})$ and the central brain (supraesophageal ganglion) was then dissected. Animals were lodged in individual containers with dim light during the time interval between training and their sacrifice. For each time point and training condition, a CT group was used. In the HDAC inhibitor effect experiments, animals were injected with 15 $\mathrm{mM} \mathrm{NaB}$ or SS and were sacrificed 15,30 , or 60 min after injection. In the experiments for HDAC inhibitor effect after weak training protocol, crabs were trained using five trials of training and injected with $15 \mathrm{mM} \mathrm{NaB}$ or SS immediately after that. Animals were sacrificed $1 \mathrm{~h}$ after injection. In all of the experiments the acetyl-H3 level was determined and values were normalized to an untreated naïve group (NV) performed simultaneously with the other groups.

\section{Histone-enriched extracts obtaining and Western blot assay}

Animals were anaesthetized by immersion in ice-cold water for two min. The central brain was then dissected. Twenty ganglions per sample were pooled in $1 \mathrm{~mL}$ of buffered crab saline solution $(\mathrm{pH}$ 7.6). Nuclear protein extracts enriched in histones were obtained as follows: All of the procedures were performed at $4^{\circ} \mathrm{C}$. Dissected supraesophageal ganglions were homogenized in buffer A (HEPES $10 \mathrm{mM} \mathrm{pH} 7.8 \mathrm{Cl} 2 \mathrm{Mg} 1.5 \mathrm{mM} \mathrm{KCl} 10 \mathrm{mM}$ DTT $1 \mathrm{mM}, 5 \mathrm{mM}$ sodium butyrate). Tissue homogenates were centrifuged at $1000 \mathrm{~g}$ for $15 \mathrm{~min}$. The pellet was resuspended in buffer A and $\mathrm{H}_{2} \mathrm{SO}_{4}$ was added to reach a $0.4 \mathrm{~N}$ concentration. Histones were acid extracted from nuclear fractions for $30 \mathrm{~min}$ at $4^{\circ} \mathrm{C}$. Acid extracts were centrifuged $5 \mathrm{~min}$ at 15,000 rpm. The supernatants were transferred to a fresh tube and proteins were precipitated with a $10 \times$ vol of acetone at $-20^{\circ} \mathrm{C}$, overnight. Precipitated proteins were collected by centrifugation at $15,000 \mathrm{rpm}$ for $15 \mathrm{~min}$. Pellets were resuspended in distilled $\mathrm{H}_{2} \mathrm{O}$. For Western blot assay, loading buffer was added and samples were incubated at $100^{\circ} \mathrm{C}$ for 5 min and immediately placed on ice. Ten micrograms of each protein sample were run on PAGE with $15 \%$ acrylamide in the resolving gel. Proteins were then electro-transferred to PVDF for immunoblotting. Western blot assay was performed with acetylspecific H3 (recognizes acetylated K9 and K14) and total H3 (CT, pan) antibodies (Upstate) following the manufacturer's protocol. The antibodies were built using a peptide corresponding to amino acids 1-20 of Tetrahymena histone H3 as immunogen, both of them having known cross-reactivity with human, mouse, rat, yeast, and chicken. Broad species cross-reactivity was expected due to high sequence homology. Detection was made with a Luminol chemiluminiscence kit (SCB) as described by the manufacturer, and the signals were digitalized by FUJI FILM-Intelligent Dark Box II apparatus with image reader LAS-1000 software. The relative optical density (ROD) was estimated using ImageJ $1.29 \times$ software. Values of ROD for the acetyl-specific $\mathrm{H} 3$ band were relative to ROD for a total $\mathrm{H} 3$ in each sample.

\section{Acknowledgments}

We thank Dr. Liliana Orelli for language correction, Angel Vidal for technical assistance, and Ignacio Schor and Alberto Kornblihtt for technical guidance in the determination of $\mathrm{H} 3$ acetylation and for generously providing one of the antibodies used. This research was supported by FONCYT PICT 26095, FONCYT PICT 2049 from ANPCYT, Argentina, UBACYT X251, Universidad de Buenos Aires, and PIP 5466, CONICET, Argentina.

\section{References}

Agranoff BW, Davis RE, Casola L, Lim R. 1967. Actinomycin D blocks formation of memory of shock-shock avoidance in goldfish. Science 158: $1600-1601$. 
Alarcon JM, Malleret G, Touzani K, Vronskaya S, Ishii S, Kandel ER, Barco A. 2004. Chromatin acetylation, memory, and LTP are impaired in $\mathrm{CBP}^{+/}$ mice: A model for the cognitive deficit in Rubinstein-Taybi syndrome and its amelioration. Neuron 42: 947-959.

Barret RM, Wood MA. 2008. Beyond transcription factors: The role of chromatin modifying enzymes in regulating transcription required for memory. Learn Mem 15: 460-467.

Colvis CM, Pollock JD, Goodman RH, Impey S, Dunn J, Mandel G, Champagne FA, Mayford M, Korzus E, Kumar A, et al. 2005. Epigenetics mechanisms and gene network in the nervous system. J Neurosci 25: 10379-10389.

Dokmanovic M, Marks PA. 2005. Prospects: Histone deacetylase inhibitors. J Cell Biochem 96: 293-304.

Feld M, Dimant B, Delorenzi A, Coso O, Romano A. 2005. Phosphorylation of extranuclear ERK/MAPK is required for long-term memory consolidation in the crab Chasmagnathus. Behav Brain Res 158: 251-261.

Fischer A, Sananbenesi F, Wang X, Dobbin M, Tsai LH. 2007. Recovery of learning and memory associated with chromatin remodelling. Nature 447: 178-182.

Freudenthal R, Romano A. 2000. Participation of Rel/NF-кB transcription factors in long-term memory in the crab Chasmagnathus. Brain Res 855: $274-281$.

Freudenthal R, Locatelli F, Hermitte G, Maldonado H, Lafourcade C,

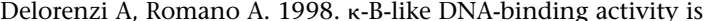
enhanced after spaced training that induces long-term memory in the crab Chasmagnathus. Neurosci Lett 242: 143-146.

Gleeson RA, Zubkoff PL. 1977. The determination of the hemolymph volume in the blue crab Callinectes sapidus, utilizing 14C-thiocyanate. Comp Biochem Physiol 56A: 411-413.

Goelet P, Castelucci VF, Schacher S, Kandel ER. 1986. The long and the short of long-term memory-a molecular framework. Nature 322: 419-422.

Guan Z, Giustetto M, Lomvardas S, Kim JH, Miniaci MC, Schwartz JH, Thanos D, Kandel ER. 2002. Integration of long-term memory-related synaptic plasticity involves bidirectional regulation of gene expression and chromatin structure. Cell 111: 483-493.

Hoeger U, Florey E. 1989. Cathecolamine degradation in the hemolymph of the Chinese crab Eriocher sinesis. Comp Biochem Physiol 92: 323-327.

Howell DC. 1987. Statistical methods of psychology, 2nd ed. Duxbury, Boston, MA.

Hsieh J, Gage FH. 2005. Chromatin remodeling in neural development and plasticity. Curr Opin Cell Biol 17: 664-671.

Korzus E, Rosenfeld MG, Mayford M. 2004. CBP histone acetyltransferase activity is a critical component of memory consolidation. Neuron 42: 961-972.

Kouzarides T. 2007. Chromatin modifications and their functions. Cell 128: 693-705.

Kumar A, Choi KH, Renthal W, Tsankova NM, Theobald DEH, Truong HT, Russo SJ, LaPlant Q, Sasaki TS, Whistler KN, et al. 2005. Chromatin remodeling is a key mechanism underlying cocaine-induced plasticity in striatum. Neuron 48: 303-314.

Levenson JM, Sweatt JD. 2006. Epigenetic mechanisms: A common theme in vertebrate and invertebrate memory formation. Cell Mol Life Sci 63 : 1009-1016.

Levenson JM, O'Riordan KJ, Brown KD, Trinh MA, Molfese DL, Sweatt JD. 2004. Regulation of histone acetylation during memory formation in the hippocampus. J Biol Chem 279: 40545-40559.

Locatelli F, Romano A. 2005. Differential activity profile of cAMPdependent protein kinase isoforms during long-term memory consolidation in the crab Chasmagnathus. Neurobiol Learn Mem 83 232-242.

Locatelli F, Lafourcade C, Maldonado H, Romano A. 2000. Characterization of cAMP-dependent protein kinase isoforms in the brain of the crab Chasmagnathus. J Comp Physiol 171: 33-40.
Locatelli F, Maldonado H, Romano A. 2002. Two critical periods for cAMP-dependent protein kinase activity during long-term memory consolidation in the crab Chasmagnathus. Neurobiol Learn Mem 77: 234-249.

Lozada M, Romano A, Maldonado H. 1990. Long-term habituation to a danger stimulus in the crab Chasmagnathus granulatus. Physiol Behav 47: $35-41$.

Marks PA, Richon VM, Miller T, Kelly WK. 2004. Histone deacetylase inhibitors. Adv Cancer Res 91: 137-168.

Merlo E, Freudenthal R, Romano A. 2002. The IкB kinase inhibitor sulfasalazine impairs long-term memory in the crab Chasmagnathus. Neuroscience 112: 161-172.

Norton VG, Imai BS, Yau P, Bradbury EM. 1989. Histone acetylation reduces nucleosome core particle linking number change. Cell 108: 449-457.

Pedreira ME, Dimant B, Maldonado H. 1996. Inhibitors of protein and RNA synthesis block context memory and long-term habituation in the crab Chasmagnathus. Pharmacol Biochem Behav 54: 611-617.

Pedreira ME, Romano A, Tomsic D, Lozada M, Maldonado H. 1998. Massed and spaced training build up different components of long-term habituation in the crab Chasmagnathus. Anim Learn Behav 26: 34-38.

Resta-Lenert S, Truong F, Barrett KE, Eckmann L. 2001. Inhibition of epithelial chloride secretion by butyrate: Role of reduced adenylyl cyclase expression and activity. Am J Physiol Cell Physiol 281: C1837-C1849.

Romano A, Lozada M, Maldonado H. 1990. Effects of naloxone pretreatment on habituation in the crab Chasmagnathus granulatus. Behav Neural Biol 53: 113-122.

Saccani S, Pantano S, Natoli G. 2001. Two waves of nuclear factor $\kappa B$ recruitment to target promoters. J Exp Med 193: 1351-1359.

Schor IE, Rascovan N, Pelisch F, Alló M, Kornblihtt AR. 2009. Neuronal cell depolarization induces intragenic chromatin modifications affecting NCAM alternative splicing. Proc Natl Acad Sci 106: 4325-4330.

Sterner DE, Berger SL. 2000. Acetylation of histones and transcriptionrelated factors. Microbiol Mol Biol Rev 64: 435-459.

Strahl BD, Allis CD. 2000. The language of covalent histone modifications. Nature 403: 41-45.

Tsankova NM, Kumar A, Nestler EJ. 2004. Histone modifications at gene promoter regions in rat hippocampus after acute and chronic electroconvulsive seizures. I Neurosci 24: 5603-5610.

Vecsey CG, Hawk JD, Lattal KM, Stein JM, Fabian SA, Attner MA, Cabrera SM, McDonough CB, Brindle PK, Abel T, et al. 2007. Histone deacetylase inhibitors enhance memory and synaptic plasticity via CREB:CBPdependent transcriptional activation. J Neurosci 27: 6128-6140.

Vettese-Dadey M, Grant PA, Hebbes TR, Crane-Robinson C, Allis CD, Workman JL. 1996. Acetylation of histone H4 plays a primary role in enhancing transcription factor binding to nucleosomal DNA in vitro. EMBO J 15: 2508-2518.

Wood MA, Kaplan MP, Park A, Blanchard EJ, Oliveira AM, Lombardi TL, Abel T. 2005. Transgenic mice expressing a truncated form of CREB-binding protein (CBP) exhibit deficits in hippocampal synaptic plasticity and memory storage. Learn Mem 12: 111-119.

Wood MA, Attner MA, Oliveira AM, Brindle PK, Abel T. 2006a. A transcription factor-binding domain of the coactivator CBP is essential for long-term memory and the expression of specifyc target genes. Learn Mem 13: 609-617.

Wood MA, Hawk JD, Abel T. 2006b. Combinatorial chromatin modifications and memory storage: A code for memory? Learn Mem 13: 241-244.

Yeh SH, Lin CH, Gean PW. 2004. Acetylation of nuclear factor-kB in rat amygdala improves long-term but not short-term retention of fear memory. Mol Pharmacology 65: 1286-1292.

Received July 8, 2009; accepted in revised form August 5, 2009. 


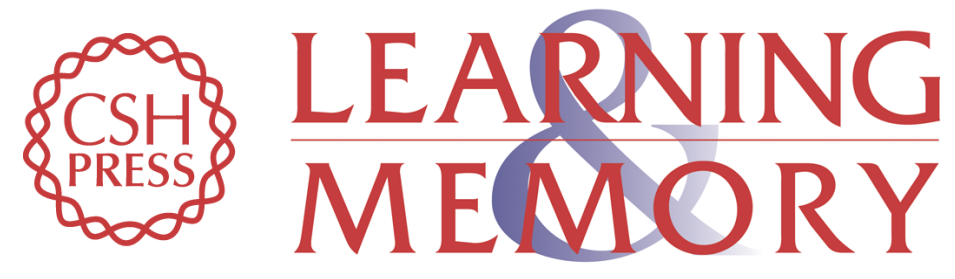

\section{Histone acetylation is recruited in consolidation as a molecular feature of stronger memories}

Noel Federman, Maria Sol Fustiñana and Arturo Romano

Learn. Mem. 2009, 16:

Access the most recent version at doi:10.1101//m.1537009

References This article cites 41 articles, 13 of which can be accessed free at:

http://learnmem.cshlp.org/content/16/10/600.full.html\#ref-list-1

License

Email Alerting Receive free email alerts when new articles cite this article - sign up in the box at the Service top right corner of the article or click here. 